\title{
O Envolvimento Paterno durante a Gestação
}

\author{
Cesar Augusto Piccinini ${ }^{12}$ \\ Milena da Rosa Silva \\ Tonantzin Ribeiro Gonçalves \\ Rita Sobreira Lopes \\ Universidade Federal do Rio Grande do Sul \\ Jonathan Tudge \\ University of North Carolina at Greensboro, EUA
}

\begin{abstract}
Resumo
O período de gestação da companheira exige uma série de adaptações por parte do pai, que precisa se preparar para os novos papéis que deverá assumir frente ao bebê e à sua nova família. Neste sentido, o presente trabalho teve por objetivo investigar como se dá o envolvimento paterno durante o $3^{\circ}$ trimestre de gestação. Participaram deste estudo 35 pais que esperavam seu primeiro filho, com idades entre 21 e 40 anos. Os pais foram entrevistados individualmente e as suas respostas foram examinadas através de análise de conteúdo. Os resultados indicaram que muitos pais estiveram envolvidos de diversas maneiras durante a gestação de suas companheiras, mostrando-se emocionalmente conectados à gestante e ao bebê. No entanto, alguns pais ainda encontravam dificuldades quanto ao envolvimento com seu filho, parecendo não percebê-lo como real e apresentando uma baixa ligação emocional com a gestação. Estes dados apontam para indícios de uma modificação quanto à paternidade já no período da gestação, a qual se encontra cada vez menos restrita ao universo feminino.

Palavras-chave: Envolvimento paterno; gestação; maternidade.
\end{abstract}

Father's Involvement during the Gestation

\begin{abstract}
The gestational period requires a series of adaptations from the father's side, who needs to prepare himself for the new role he will assume vis-à-vis the baby and his/her new family. The present study aimed at investigating father's involvement during the third trimester of gestation. Thirty-five fathers, aged 21 to 40, who were expecting their first child, took part in the study. The fathers were interviewed individually and their answers were examined through content analysis. Results indicated that many fathers were involved in different ways during their partner's pregnancy, being emotionally connected with the baby and their partner. However, some fathers still found difficulties concerning involvement with their child, seeming not to perceive him/her as real and showing low emotional connection with pregnancy. These data point to signs of change concerning fatherhood during pregnancy, which is increasingly less restricted to the feminine domain.

Keywords: Father's involvement; gestation; fatherhood.
\end{abstract}

O período de transição para a parentalidade exige uma série de adaptações e mudanças por parte dos futuros pais, tanto em nível psicológico e biológico como social (Salmela-Aro, Nurmi, Saisto \& Halmesmãki, 2000). A gestação funciona, para os pais, como um período de preparação para os novos papéis que deverão assumir, frente ao bebê e a tudo que ele irá exigir. A elaboração das fantasias e sentimentos, a revisão da sua própria infância e dos papéis parentais, bem como as preocupações decorrentes desta transição, são algumas das características desta etapa do desenvolvimento (Brazelton, 1988; Levy-Shiff \& Israelashvili, 1988).

\footnotetext{
${ }^{1}$ Gostaríamos de agradecer ao Conselho Nacional de Pesquisa - CNPq a a Spencer Foundation - EUA, que deram apoio para a análise dos dados e redação deste artigo. As idéias contidas no artigo são de inteira responsabilidade dos autores.

${ }^{2}$ Endereço para correspondência: GIDEP, Instituto de Psicologia, Universidade Federal do Rio Grande do Sul, Rua Ramiro Barcellos, 2600, 90350 003, Porto Alegre, RS.E-mail:piccinini@portoweb.com.br
}

A trajetória masculina rumoà parentalidade difere da feminina, pois somente a mulher poderá sentir o filho crescer dentro de si, dar à luz e amamentá-lo. Por esta razão, de acordo com Maldonado, Dickstein e Nahoum (1997), muitas vezes os pais não conseguem criar um vínculo concreto e sólido com o bebê. Para estes autores, a formação do vínculo entre pai e filho costuma ser mais lenta, consolidando-se gradualmente após o nascimento e no decorrer do desenvolvimento da criança. $\mathrm{O}$ fato de o pai não contar com a realidade das mudanças corporais e do desenvolvimento do bebê no seu próprio corpo, pode, ainda, suscitar sentimentos de ciúme, inveja, ansiedade e solidão no homem (Delmore-Ko, Pancer, Hunsberger \& Pratt, 2000; Maldonado \& cols., 1997). Segundo Brazelton (1988), a competição e a exclusão também são sentimentos freqüentes e esperados nos futuros pais, não somente porque a mulher tende a desviar suas energias e atenção para o bebê, mas também porque ela se torna o centro das atenções de todos, sendo que poucos se interessam pelos sentimentos do futuro pai durante 
este período de adaptação. No entanto, o homem deve fazer adaptações similares às da mulher, e enfrenta dúvidas e angústias também semelhantes.

Nas sociedades ocidentais, os papéis assumidos por pais e mães têm sido tradicionalmente diferentes. A mãe possui o papel de cuidadora primária e o pai, o de provedor das necessidades materiais da familia, apoiando indiretamente a díade mãe-bebê (De Martini, 1999; Levy-Shiff \& Israelashvili, 1988). Além do apoio material, o suporte emocional à gestante também se constitui em uma importante função atribuída ao pai (Klaus \& Kennell, 1992). Neste sentido, segundo os autores, a aceitação do bebê pelo companheiro é um fator significativo para o desenvolvimento do apego materno ao bebê. Sua ajuda se dá, principalmente, através do apoio à mulher na harmonização de seus conflitos da infância em torno da maternidade.

Recentemente, autores como Parke (1996) assinalaram que os pais vêm assumindo outras tarefas com relação aos filhos, sendo que o estereótipo do pai incompetente e desinteressado em relação aos cuidados primários não vem sendo confirmado por muitos estudos recentes. Segundo o autor, o grande envolvimento das mulheres no campo profissional e o novo papel social do trabalho feminino, dentre outros fatores sócioeconômicos, vêm abrindo espaços para a participação dos pais nos cuidados com seus filhos. Desta forma, os pais estariam mais ativos em sua parentalidade, exercendo influências diretas sobre o desenvolvimento de seus filhos. Conforme Brazelton (1988), existe uma nova consciência de que criar um filho é também função do pai, mas ainda não há clareza quanto a este novo papel, e aqueles homens que assumem esta responsabilidade nem sempre recebem apoio social.

Em relação a estas mudanças no papel do pai, tem sido amplamente discutido o conceito de envolvimento paterno. Lamb, Pleck, Charnov e Levine (1985) definem este conceito a partir de três dimensões de avaliação do comportamento paterno: interação, acessibilidade à criança e responsabilidade. A interação refere-se ao contato direto com o filho, em cuidados e atividades compartilhadas. A acessibilidade concerne à presença ou disponibilidade para a criança para possíveis interações. Já a responsabilidade diz respeito ao papel que o pai exerce garantindo cuidados e recursos para a criança. De acordo com Parke (1996), por muito tempo este conceito foi tratado de forma apenas quantitativa, medido através do número de horas que o pai passava com a criança em cuidados e outras atividades. Atualmente, a avaliação do envolvimento paterno inclui também aspectos qualitativos, como a qualidade e o conteúdo do envolvimento.

Enquanto o envolvimento paterno após o nascimento do bebê tem recebido a atenção de vários autores, a participação do pai na gestação continua pouco estudada. Durante a gestação, o envolvimento paterno deve ser compreendido de modo peculiar, pois o vínculo entre pai e filho é indireto, mediado pela mãe. Parke (1996) aborda o envolvimento paterno na gestação, ressaltando que os casais, e não apenas as mulheres, ficam grávidos, e que as mudanças que ocorrem com os futuros pais durante a gravidez não são independentes das mudanças por que passam as próprias gestantes. Os pais podem, inclusive, desenvolver a Síndrome de Couvade, apresentando sintomas físicos e psicológicos semelhantes - e concomitantes - aos das mulheres. Num estudo brasileiro investigando este conceito em trinta futuros pais, De Martini (1999) verificou a presença de indicadores desta síndrome em aproximadamente metade dos participantes de sua pesquisa. $\mathrm{O}$ envolvimento paterno na gestação não se refere apenas a comportamentos - como acompanhar consultas e ecografias - mas também a um envolvimento emocional, sendo que estes aspectos não estão necessariamente relacionados (May, 1982). Desta forma, entende-se que o envolvimento do pai na gestação pode ser compreendido através da sua participação em atividades relativas às gestantes e aos preparativos para a chegada do bebê, do apoio emocional proporcionado à mãe, da busca de contato com o bebê, bem como das preocupações e ansiedades destes pais.

O envolvimento paterno pode variar bastante ao longo da gestação, de acordo com o desenvolvimento do bebê, bem como conforme as características de cada pai. Com relação às diferenças ao longo da gravidez, May (1982) sugere um padrão de mudanças seqüenciais no envolvimento emocional dos pais, constituído de três fases. A primeira destas compreende o período desde a suspeita de gravidez - acompanhada de um grande impacto inicial - até a sua confirmação, quando os pais podem experimentar reações de desconforto, estresse e ambivalência. Na segunda fase, os pais ainda não sentem a gestação como uma realidade, uma vez que os sinais físicos ainda não são evidentes. Em decorrência disto, a distância emocional é a característica mais marcante deste período. $\mathrm{Na}$ última fase, os homens vivenciam a gestação como real e importante em suas vidas, conseguindo definir-se como pais. Normalmente, segundo May, este último estágio ocorre no terceiro trimestre da gestação, quando o nascimento do bebê está mais próximo e os pais tornam-se mais participativos nos preparativos para a sua chegada.

No entanto, conforme a autora, os pais diferem consideravelmente no modo como atravessam estes estágios, havendo pais que não conseguem realmente envolver-se com o seu filho em nenhum momento da gestação. Segundo Szejer e Stewart (1997) e Souza (1997), alguns pais sentem-se profundamente envolvidos com questões da gestação, procurando participar o máximo possível e mostrando uma grande disponibilidade emocional para esta experiência. Maldonado e colaboradores (1997) afirmam existir pais que procuram sentir o bebê na barriga da mulher, acompanham as consultas pré-natais, ajudam a compor o enxoval e a organizar o quartinho do bebê. Eles podem mostrar maior interesse por bebês, gravidez e parto lendo livros sobre o assunto e buscando todas as informações disponíveis (Maldonado \& cols., 1997; Parke, 1996). Segundo os 
autores, o acompanhamento às ecografias, que permitem aos casais assistirem em videoteipe ao desenvolvimento e aos movimentos fetais, costumam encorajar o interesse e envolvimento dos pais.

Alguns pais, por outro lado, logo antecipam dificuldades financeiras que podem decorrer das despesas com o bebê e aumentam sua carga de trabalho, muitas vezes assumindo um segundo emprego. Esta sobrecarga de trabalho, e conseqüente afastamento do lar, pode ser um sinal de preocupação e ansiedade do futuro pai (Parke, 1996). Este autor afirma que os pais podem experienciar muita ansiedade durante a gestação, preocupandose com o parto e a saúde do bebê, apesar de que as preocupações de ordem financeira se destacariam, sendo as mais prevalentes. Brazelton (1988), por sua vez, acrescenta que as preocupações com o aumento das responsabilidades para com a familia e com as possíveis conseqüências nas relações sexuais também são recorrentes nos pais. Outras reações dos pais observadas por Szejer e Stewart (1997) e Souza (1997) são os sentimentos de exclusão e inutilidade, e fuga de todos os aspectos da preparação para a chegada do bebê, e, algumas vezes, do próprio ambiente familiar. Souza apontou ainda que alguns pais colocam-se como espectadores desinteressados, justificando que os problemas relativos à gestação são de responsabilidade da mulher.

A literatura revisada também indica que o envolvimento do pai já na gestação parece ter importantes implicações para o desenvolvimento das primeiras relações pai-bebê (Brazelton \& Cramer, 1992) e mãe-bebê (Brazelton, 1988; Winnicott, 1966). Neste sentido, o presente trabalho teve por objetivo investigar e descrever o envolvimento paterno no terceiro trimestre de gestação.

\section{Método}

\section{Participantes}

Participaram deste estudo 35 pais que esperavam seu primeiro filho, com idades entre 21 e 40 anos. A idade média foi de 30,3 anos ( $d p=5,4)$. Todos viviam com a mãe do bebê, a qual não apresentava problemas de saúde durante a gestação. Os participantes eram de níveis sócio-econômicos variados e residiam na região metropolitana de Porto Alegre. Em termos de escolaridade, os pais variaram entre ensino fundamental incompleto $(14,3 \%)$ e completo $(8,6 \%)$, ensino médio incompleto $(2,8 \%)$ e completo $(22,9 \%)$, superior incompleto $(25,7 \%)$ e completo $(17,1 \%)$, e pós-graduação $(8,6 \%)$. Houve uma variação similar em termos do status ocupacional do pai, variando de profissões de "baixo status" (37,1\% dos pais estavam em profissões classificadas de 1 a 4 na escala de Hollingshead, 1975), "status médio" (28,6\% em profissões classificadas de 5 a 6$)$, e de "alto status" (25,7\% em profissões classificadas de 7 a 9). Não foi possível classificar o status ocupacional dos demais pais $(8,6 \%)$ devido à falta de informações.
Utilizamos a escala de dois fatores de Hollingshead (1975) envolvendo a combinação da escolaridade e ocupação do pai para classificar o seu nível sócio-econômico de forma mais acurada. Esta classificação revelou uma distribuição bastante uniforme, com $26,7 \%$ dos pais categorizados como "profissionais" (major business and professional), 26,7\% como "técnicos" (medium business, minor professional, technical), $22,9 \%$ como "artesãos qualificados, comerciantes, etc.", e $17,1 \%$ em profissões "semi-qualificadas" ou "não qualificadas". Os 8,6\% restantes dos pais, três no total, dos quais não havia informação suficiente relativa às suas ocupações tiveram uma distribuição relativamente uniforme em termos de escolaridade, com um pai tendo deixado a escola sem ter concluído o ensino fundamental, um com ensino médio completo, e um com curso superior incompleto.

Apesar de a escala de Hollingshead ter sido desenvolvida há quase 30 anos e ter se baseado no censo norte-americano, há alguma evidência de que ela pode ser apropriada para uso nas famílias sul americanas. Pascual, Galperin e Bornstein (1995) encontraram uma alta correlação $(0,88)$ entre a classificação de Hollingshead e um índice argentino de NSE. Além disso, Ribas, Seidl de Moura e Bornstein (no prelo) encontraram que a classificação de Hollingshead se correlacionava significativamente $(0,36)$ com um teste de conhecimento sobre paternagem (Parenting Knowledge) utilizado com uma amostra de pais brasileiros. Embora Ribas e colaboradores estivessem interessados em conhecimento sobre paternagem, ao invés de práticas efetivas, medidas da escolaridade das mães $(0,41)$ e dos pais $(0,34)$ não predisseram conhecimento significativamente melhor do que a escala de Hollingshead.

A amostra foi selecionada, com base nos critérios descritos acima, dentre os participantes de um projeto intitulado Estudo Longitudinal de Porto Alegre: Da Gestação à Escola (Piccinini, Tudge, Lopes \& Sperb, 1998). Este estudo acompanha aproximadamente 100 famílias, cujas gestantes eram primíparas, representando várias configurações familiares, de diferentes idades, escolaridade e níveis sócioeconômicos ${ }^{3}$. O contato inicial para participar deste estudo foi feito com a gestante no $3^{\circ}$ trimestre de gestação, através de hospitais da rede pública e privada de Porto Alegre, postos de saúde, anúncios em jornais, e por indicação.

\section{Procedimentos e Instrumentos}

O convite para os pais participarem do presente estudo era feito através da gestante. No primeiro contato com a gestante, eram explicados a ela os objetivos do estudo e realizada a Entrevista de contato inicial (GIDEP, 1998a). Através desta

\footnotetext{
${ }^{3}$ Fazem parte deste projeto, além dos 35 casais selecionados para este estudo, famílias constituídas por pais adolescentes, pais recasados, mães solteiras, e com crianças portadoras de Síndrome de Down e doenças crônicas.
} 
entrevista, buscava-se investigar se a gestante era primípara, sua idade gestacional e seu estado de saúde, a fim de verificar se a familia se enquadrava nos critérios para constituição da amostra descritos acima. Uma vez atendendo as características exigidas para participar do estudo, era marcado um encontro na residência dos participantes, quando as gestantes e os pais assinavam um consentimento informado e era realizada a Entrevista de dados demográficos (GIDEP, 1998b). Esta entrevista foi usada para se obter informações demográficas adicionais, como idade, escolaridade, estado civil, ocupação, religião e grupo étnico.

Os pais também responderam à Entrevista sobre a Gestação e as Expectativas do Futuro Pai (GIDEP, 1998c) ${ }^{4}$. Esta entrevista semi-estruturada buscava examinar as percepções do pai em relação ao planejamento da gravidez, sua aceitação, a imagem que o pai fazia da gestante, seu estado de humor predominante durante a gestação e a gravidez no contexto da relação com a esposa e demais membros de sua família. Além disso, abordava as percepções e fantasias do pai sobre o bebê e a paternidade. Para fins do presente estudo foram examinados apenas os relatos dos pais a respeito do seu envolvimento na gestação da esposa.

\section{Resultados}

Foi realizada uma análise de conteúdo (Bardin, 1977) para examinar o relato dos pais sobre seu envolvimento na gestação da esposa. Com base na literatura (De Martini, 1999; Parke, 1996) e nas respostas dos pais à entrevista foram criadas três categorias temáticas: 1) Participação do pai na gravider, 2) Interaşão do pai com o bebê; e 3) Preocupações do pai durante a gestagão. Estas foram divididas em subcategorias conforme explicitado a seguir. Dois juízes classificaram separadamente os relatos dos pais em cada categoria e subcategoria e, em casos de discordância, usou-se um terceiro juiz. Apresentase, a seguir, a caracterização de cada uma das categorias e subcategorias, buscando exemplificá-las através de relatos dos próprios pais. Ao final, são apresentadas tabelas com a distribuição das respostas em cada categoria e subcategoria.

\section{1) Participação do pai na gravidez.}

Pôde-se verificar que os pais participam de inúmeras formas na gravidez de suas companheiras, tanto de modo direto, através de comportamentos como acompanhar as ecografias e consultas, como de modo indireto, oferecendo-se como uma figura de apoio para a gestante e expressando o seu envolvimento emocional. Para fins de análise esta categoria foi dividida em 10 subcategorias: apoio emocional à gestante; apoio material à gestante; referir-

\footnotetext{
${ }^{4}$ Entrevista semelhante era realizada com a gestante. O casal também respondia à Narrativa Conjunta do Casal e ao Genograma Familiar do Casal. Contudo, os dados destes instrumentos não serão analisados no presente estudo.
}

se como grávido; acompanhamento às consultas pré-natais; acompanhamentos às ecografias; envolvimento nos preparativos para a chegada do bebê; busca de informaçōes sobre bebês e gravidezz: desejo de assistir ao parto; participação em curso de gestantes; conhecimentos sobre o seu bebê. Inclui-se aqui a subcategoria referir-se como grávido, pois o sentimento de estar também gestando o bebê constitui-se em um indicativo do envolvimento emocional do pai na gestação. De acordo com Parke (1996), desde a década de 1970 a gestação passou a ser entendida como uma questão concernente à famillia, e não apenas à mãe. Desta forma, segundo o autor, não é somente a mãe, mas sim o casal que ficaria grávido.

Diversos relatos de apoio emocional à gestante foram verificados nas entrevistas analisadas. Este apoio engloba as verbalizações dos pais referentes a tranqüilizar e acalmar a companheira, elogiar as modificações no seu corpo, estar mais disponível, conversar com ela e ser mais paciente e compreensivo: Demonstrar dentro do possivel tranqüilidade, porque já chega a ansiedade normal dela, então se eu também comesar a demonstrar demais a ansiedade minha, que também tem Mas en tenho só elogiado, acho ela super bonita assim, bacana, todas as mudancas no corpo dela, eu acho super bacana, e eu tenho expressado isto, faco questão de falar porque eu tenho elogiado; Eu tenho que mudar meus bábitos até, por causa da carência dela, eu até há um tempo atrás comentei com ela, não vou mais ligar a televisão, só tu liga, porque eu tô disponivel, não tô entretido olhando televisão, olhando um jogo.

$\mathrm{O}$ apoio material àgestante também foi bastante citado, referindose ao auxílio prestado à companheira, dada a sua atual impossibilidade de realizar algumas tarefas, como serviços domésticos, dirigir e cuidados pessoais incluindo os cuidados com a saúde da companheira: Quando ela se sente mal eu faço uma sopinha... en faço chazinho para ela..., tá mal eu vejo o que está acontecendo, se tem que buscar remédio eu busco; O serviço mais pesado, tipo varrer os carpetes... en vou lá e faço, porque eu sei que ela não vai poder fazer; Então claro, eu não tenho o mesmo ânimo que ela teria pra fazer as coisas [afazeres domésticos], mas tento ajudar.

A subcategoria referir-se como grávido engloba expressões, utilizadas por alguns pais, nas quais explicitamente se colocavam como estando grávidos, referindo, ou não, sintomas físicos: $A$ sensação minha é como se eu tivesse grávido, só sem nenê na barriga; Então, é interessante porque o homem fica grávido também, é impressionante, é uma coisa parece hormonal não é uma coisapsicológica, sabe, fraqueza, pressão baixa e tudo. $\mathrm{O}$ acompanhamento às consultas e exames pré-natais foi bastante relatado pelos pais como uma forma de participação na gravidez, bem como as reações desencadeadas por esta situação: Eu fui no médico, só escutei o aparelhinho do coração... ah, me senti assim, diferente né... é uma sensação diferente; Não [acompanba a esposa], só quando eles sugerem que eu vá, alguma coisa, que pedem pra eu ir, eu vou. $\mathrm{Na}$ primeira, que era pra confirmar a gravidez... tive que ir.

$\mathrm{O}$ acompanbamento às ecografias foi relatado por quase todos os pais, assim como as reações desencadeadas por estas participações: desde tranqüilidade, felicidade, emoção, sensação de presença concreta do bebê, até relatos de incompreensão 
das imagens. Alguns pais ainda gravaram as ecografias: Quando a gente viu na imagem, porque teve um momento lá que ele virou o rostinho e abria e fechava os olhos. Bah, aquilo ali era... é uma emocão, é unica; Sempre foi assim, aquele medo inicial, pra ver se tava bem e depois que o médico ia falando, tá aqui o coração, "tá aqui a cabesca, tá aqui a perninha, os bracos, as mãozinhas perfeitas, a gente vai se tranqüilizando e cada ver. querendo ver mais"; "Ah, bah, parecia que ele tava conosco ali... Ele tava sabendo que a gente tava enxergando ele... Então foi assim, a presença dele foi muito marcante; É que a gente é leigo no assunto, tu vai lá, tu vê na televisão as imagens, mas tu não sabe onde é que está. Ele mostra lá, "aquie é aperninha, aqui é a cabecinha, aqui é a coluna, aqui é não sei o que"é bem dificil.

O envolvimento nos preparativos para a chegada do bebê foi manifestado através do relato da participação do pai na organização da casa e do quartinho, planejamento de férias, escolha da maternidade e da creche, compras para o bebê e preparação da sua "malinha" para o hospital: A gente soube da gravidez a gente comecou a planejar a casa, né, trocar aqui, fazer o quarto dela, fazer tudo pra ela; Que agora a gente se preocupa mais em ter lugar e em conservar o ambiente, en tenho que me desfazer de algumas coisas que eu não queria; Lá [na creche] é bom, eu conheço o pessoal de lá, tem bastantepessoas pra atender...já tá tudo certinho [para colocar o bebê], vou lá quando já tiver certo. Os participantes também verbalizaram interesse na busca de informações sobre bebês e gravidez em revistas, jornais, programas de tv e em pessoas mais experientes: A gente tem se preparado bastante, até com algumas leituras, tem bastante livros... a gente procura também se informar com os pais da gente.

Poucos pais manifestaram desejo de assistir ao parto, bem como a participação em cursos de gestantes. Devido ao acompanhamento de muitos pais às consultas médicas e às ecografias, e a partir de suas próprias impressões, alguns pais demonstraram possuir diversos conhecimentos sobre o seu bebê: Eu já sei que ele tem dois quilos, que o fêmur dele tem seis centímetros. Já estão me dizendo que ele é cabeçudo. Que vai ter um perão... Ele não é nem grande nem pequeno; Tá gordo, saudável, tá lindo, esperto, já tem praticamente a personalidade dele. Ao mesmo tempo, outros pais não manifestaram este tipo de conhecimento: Agora não sei nada [sobre o bebê], nada mesmo, só sei que tá bem, saudável.

A Tabela 1 apresenta as porcentagens e freqüências de respostas para a categoria Participação do pai na gravidez: Como pode ser observado, o acompanhamento às ecografias foi a forma de participação mencionada pelo maior número de pais (91\%), seguida pelas atitudes de apoio emocional à gestante $(83 \%)$. Outras formas de participação do pai mostraram-se ainda bastante presentes nos seus relatos: $68 \%$ destes relataram acompanhar a gestante às consultas pré-natais; $60 \%$ afirmaram apoiá-la materialmente; $57 \%$ descreveram seu envolvimento nos preparativos para a chegada do bebê e 37\% relataram conhecimentos sobre o seu bebê. Outros modos de participação apresentaram uma freqüência bastante baixa, como o desejo de assistir ao parto $(17 \%)$, referir-se como grávido $(14 \%)$, busca de informações sobre o bebê (11\%) e participação em curso de gestantes $(6 \%)$. Considerando o total de respostas (214) envolvendo sua participação na gestação, cada pai relatou, em média, aproximadamente seis respostas de participação. No que se refere às ocorrências de respostas, a Tabela 1 mostra uma distribuição de porcentagens semelhante à descrita acima. Apoio emocional à gestante e acompanhamento às ecografias destacamse entre as subcategorias mais mencionadas.

\section{2) Interação do pai com o bebê}

Grande parte dos pais referiu interagir com o seu filho, seja buscando ativamente este contato ou reagindo às manifestações do bebê no útero. Para fins de análise, esta categoria foi dividida em três subcategorias: reaçōes frente às manifestaçöes do bebê; busca ativa pelo pai de interasão com o bebê; e pouca ou nenbuma interasão.

Tabela 1

Porcentagem e Freqüência de Respostas para a Categoria "Participaşão do Pai na Gravidez" (N=35

\begin{tabular}{llc}
\hline Participação & Número de pais & Total de respostas \\
\hline Acompanhamento às ecografias & $91 \%(32)$ & $19 \%(41)$ \\
Apoio emocional & $83 \%(29)$ & $23 \%(50)$ \\
Acompanhamento às consultas & & \\
pré-natais & $68 \%(24)$ & $14 \%(31)$ \\
Apoio material & $60 \%(21)$ & $12 \%(26)$ \\
Envolvimento nos preparativos & $57 \%(20)$ & $14 \%(31)$ \\
Conhecimentos sobre o seu bebê & $37 \%(13)$ & $7 \%(16)$ \\
Assistir o parto & $17 \%(6)$ & $3 \%(6)$ \\
Referir-se como grávido & $14 \%(5)$ & $3 \%(7)$ \\
Busca de informações sobre bebês & $11 \%(4)$ & $2 \%(4)$ \\
Curso de gestantes & $6 \%(2)$ & $1 \%(2)$ \\
\hline Total & 35 & 214 \\
\hline
\end{tabular}

Nota. 1) Cada pai pode ter apresentado respostas classificadas em mais de uma categoria; 2)

Cada pai pode ter apresentado mais de uma resposta classificada na mesma categoria ao longo da entrevista 
As reaçöes frente às manifestações do bebê referidas pelos pais dizem respeito às suas sensações, impressões e sentimentos despertados pela observação das manifestações do bebê. Estas reações compreendem: emoção e alegria, atribuição de características de personalidade, certificação da presença do bebê, impressão de que ele reconhece o pai e responde - ou não - aos seus estímulos: Não é quando tu quer que ele mexe, é quando ele quer.; O bom de quando tu sente mexer é que dai tu tem certeza que ele tá ali dentro. Além disso, alguns pais reclamaram da dificuldade de sentir os movimentos e reações do filho: Ele mexe, a K. me fala, eu vou lá e toco, mas na verdade eu sinto pouco, eu não consigo sentir; Eu não sou muito atraente pra ela [filha], se eu ficar conversando com ela, não se mexe muito, então eu tenho que ficar quietinho pra ela poder se mexer.

A subcategoria busca ativa de interação com o bebê foi também bastante citada pelos participantes, e abrange os comportamentos que buscam um contato mais próximo com o bebê na barriga da mãe, como conversar, ler histórias, acariciar e beijar a barriga da gestante: Bah, o cara fica ali, bota a mãozinha, conversa né... Eu fico trovando, conversando com ele um tempão, ali, é muito bom; Já leio bistorinha agora que tá na barriga. Foram observados alguns relatos de pouca ou nenbuma interaşão com o bebê, o que pode decorrer de dificuldades dos pais em relação a esta atividade como, por exemplo, não se sentir à vontade: $A$ mãe conversa, bastante até. E eu não... não é de mim assim; Toco muito pouco. É que ela reclama muito... que en teria que tocar mais, conversar mais, só que não, realmente não; Ela pede para eu conversar com a criança, eu não tenho jeito né, fico meio sem jeito.

A Tabela 2 apresenta as porcentagens e freqüências de respostas para a categoria Interaşão com o bebê. Pode-se verificar que a maior parte dos pais relatou ter tido algum tipo de reação frente às manifestações do bebê $(88 \%)$ e também ter buscado ativamente interação com o bebê ( $80 \%$ ). Somente $17 \%$ dos pais consideravam ter pouca ou nenhuma interação com o bebê na barriga da mãe, embora estes tenham referido pelo menos uma das subcategorias apontadas acima em outros momentos da entrevista. Considerando o total de respostas (81) às duas primeiras subcategorias, cada pai referiu em média duas situações de interação com o bebê. Com relação à ococrrência de respostas, a
Tabela 2 mostra uma distribuição semelhante em relação às porcentagens envolvendo número de pais.

\section{3) Preocupacões do pai durante a gestação}

A maioria dos pais mencionou alguma preocupação em relação ao período da gestação de sua companheira, nascimento do filho e/ou exercício da paternidade. Seis subcategorias foram utilizadas para classificar as preocupações em relação: à gestante; ao bebê; ao parto; àsfinancas; ao aumento das responsabilidades; eàimexperiência.

Os pais relataram muitas preocupações em relação à gestante, que envolviam a sua saúde, seu bem-estar, restrições impostas pela gestação e necessidade de um maior apoio afetivo e material: Ela não podepegarpeso, eu não deixo, a limpeza da casa eu faço... não gosto que ela ande na rua sozinha, dirigirmuito menos; Eu tenho uma preocupação de contato... e ajudar pra ela ter uma coisa bem tranqüila Também foram bastante mencionadas pelos pais as preocupacōes em relação ao bebê, referindo-se à saúde do bebê durante a gestação e ao nascer, e ao medo de malformações, síndromes, prematuridade e aborto: Eu tinha preocupação quanto a formação dele, né, a formação dos membros, tudo direitinbo; No início en tive até [preocupação] porque ela perdeu o primeiro, ela teve uma gravidez antes... então a gente fica com aquele receio; Será que ele vai ser... não tem perigo né, de nascer com Síndrome de Down. As preocupações em relação ao parto, em particular em relação ao trabalho de parto e/ou tipo de parto, como a necessidade de uma cesariana, foram também manifestados pelos pais: Eu tenho medo do parto, de dar uma complicação, alguma coisa no parto; Ela não se virou, eu tô com medo de ter que ser uma cesárea... tem que cortar, abrir, é uma coisa mais complicada.

Com relação às preocupações financeiras, os pais verbalizaram suas inquietações em torno da sua capacidade financeira de se preparar para a chegada do filho e, futuramente, sustentá-lo. Enquanto alguns pais manifestaram necessidade de aumentar a renda, através de um novo emprego, outros temiam perder o emprego atual: Claro, o cara tem assim preocupações financeiras... ninguém tá garantido, não tenho serviço público e eu trabalbo num órgão privado e a qualquer momento eles podem me botar pra rua... dai eu tive um certo medo assim; Eu acho que em moradia e em condições de vida eu acho que já começa por aí. Aí depois que nascer, aí sim, aí já vem o aspecto de comida, de roupa, de sustento. As preocupacões com o aumento das

Tabela 2

Porcentagem e Freqüiencia de Respostas para a "Categoria Interação do Pai com o Bebề" (N=35)

\begin{tabular}{lll}
\hline Interação do pai com o bebê & Número de pais ${ }^{1}$ & Total de respostas $^{2}$ \\
\hline Reações às manifestações do bebê & $88 \%(31)$ & $53 \%(47)$ \\
Busca ativa de interação & $80 \%(28)$ & $38 \%(34)$ \\
Pouca ou nenhuma interação & $17 \%(6)$ & $9 \%(8)$ \\
\hline Total & 35 & 89 \\
\hline
\end{tabular}

Nota.1) Cada pai pode ter apresentado respostas classificadas em mais de uma categoria; 2) Cada pai pode ter apresentado mais de uma resposta classificada na mesma categoria ao longo da entrevista. 
Tabela 3

Porcentagem e Frequiência de Respostas para a Categoria "Preocupações do Pai durante a Gestação" (N=35)

\begin{tabular}{lcc}
\hline Preocupações do pai & Número de pais $^{1}$ & Total de respostas $^{2}$ \\
\hline Em relação ao bebê & $68 \%(24)$ & $23 \%(27)$ \\
Em relação à gestante & $54 \%(19)$ & $26 \%(30)$ \\
Financeiras & $31 \%(11)$ & $11 \%(13)$ \\
Relatam não ter preocupações & $31 \%(11)$ & $11 \%(13)$ \\
Em relação ao parto & $28 \%(10)$ & $10 \%(12)$ \\
Em relação ao aumento das responsabilidades & $25 \%(9)$ & $10 \%(12)$ \\
Em relação à inexperiência & $20 \%(7)$ & $6 \%(7)$ \\
\hline Total & 35 & 114
\end{tabular}

Nota.1) Cada pai pode ter apresentado respostas classificadas em mais de uma categoria; 2) Cada pai pode ter apresentado mais de uma resposta classificada na mesma categoria ao longo da entrevista

responsabilidades também fizeram-se presentes nos relatos dos pais. Estas relacionaram-se à maior responsabilidade em manter seu emprego, em ter condições de prover bens materiais e à estabilidade no relacionamento do casal e sua reorganização, para se constituir como uma familia: Preocupação de ver como é que a gente ia fazer, é uma responsabilidade, né. Agora não dava mais para voltar atrás; Porque a gente não vai pensar que somos só nós dois, a gente vai ter que planejar tudo em três.

Alguns pais citaram também preocupações com a inexperiência, referindo-se às habilidades necessárias aos cuidados com o bebê: Isso vai ser dificil, vai ser duro, porque en sou atrapalhado pra caramba, en vou ter que aprender, esses esquemas, ter habilidade pra trocar fralda, mas en quero; Dai eu vou ficar preocupado, nervoso, o primeiro filho, a gente não sabe o que faz, marinheiro de primeira viagem é isso. Por fim, foram categorizadas as verbalizações em que os pais referiram não ter preocupações com a gestação. Estas manifestações de aparente tranqüilidade eram relacionadas, pelos próprios pais, às suas impressões e/ou características, ou a informações médicas que afastavam a possibilidade de complicações: Não tenho preocupações. Eu acho que tá tudo indo normal, todos os passos que tão planejados já estão bem, indo bem; Eu penso tudo o melhor, não penso que de repente possa acontecer alguma coisa, eu penso que vai dar tudo certo.

A Tabela 3 apresenta as porcentagens e freqüências de respostas para a categoria Preocupações do pai durante a gestação. Como pode ser visto na Tabela 3 , as preocupações em relação ao bebê foram mencionadas por um grande número de pais (68\%), seguidas pelas preocupações em relação à gestante (54\%). Outras preocupações mostraram-se também bastante freqüentes no relato dos pais, entre elas as preocupações financeiras (31\%); com o parto (28\%); com o aumento das responsabilidades (25\%) e com a inexperiência $(20 \%)$. Cabe destacar que um número expressivo de pais (31\%) referiu literalmente não ter preocupações durante a gestação, embora grande parte deles tenha manifestado algumas preocupações ao longo da entrevista. Deste modo, a inclusão dos pais na categoria Relatam não ter preocupações não significa, necessariamente, que estes pais não tenham referido preocupações. Nos casos em que elas foram explicitadas, sua ocorrência foi computada nas outras categorias.

Considerando o total de preocupações (101) classificadas nas subcategorias, cada pai relatou em média três preocupações. No que se refere às ocorrências de respostas, a Tabela 3 mostra uma distribuição de porcentagens semelhante à descrita acima. Preocupações com o bebê, com a gestante e com as finanças destacam-se entre as subcategorias mais mencionadas.

\section{Discussão}

Por longo tempo, o estudo da relação mãe-bebê foi o foco central de interesse no desenvolvimento infantil, sendo que apenas recentemente a relação pai-bebê começou a ser mais extensamente estudada (Costa \& Katz, 1992; Lewis \& Dessen, 1999). No período gestacional, essa "exclusão" do pai ainda é bastante preponderante, sendo que a maior parte dos estudos atuais centra-se na relação pai-bebê após o nascimento (De Martini, 1999). No presente estudo, buscou-se demonstrar que os pais, e não somente as mães, passam por uma série de transformações durante o período gestacional no sentido da constituição da paternidade e, deste modo, envolvem-se e participam da gravidez física e emocionalmente. Para tanto, utilizou-se o conceito de envolvimento paterno (Lamb \& cols., 1985), explorando suas aplicações na fase de gestação. Este conceito, como referido anteriormente, diz respeito à interação, acessibilidade e responsabilidade do pai para com seu filho. $\mathrm{O}$ envolvimento paterno durante a gestação pode manifestar-se através de diferentes comportamentos e sentimentos do pai em relação à gestante e ao bebê, como suas preocupações, sua participação direta na gestação e a interação pai-bebê.

Os resultados do presente estudo revelaram que muitos pais estavam envolvidos de diversas maneiras com a gestação 
de seu filho(a), à semelhança do que tem sido encontrado por outros autores (De Martini, 1999; Parke, 1996). Com relação à participação dos pais na gestação, salientaram-se as verbalizações que referiam apoio emocional e material à gestante, acompanhamento às consultas pré-natais e ecografias, e envolvimento com os preparativos para a chegada do bebê, o que corrobora os achados de De Martini. Quase todos os participantes relataram apoiar emocionalmente sua companheira, estando mais disponíveis, pacientes e compreensivos. De acordo com Pleck (1997), os homens tenderiam a reagir positivamente ao aumento das necessidades emocionais de suas esposas durante a gestação. Do mesmo modo, Krob (1999) afirmou que a maioria dos participantes de seu estudo demonstrou sensibilidade para percebermudanças emocionais em sua esposa durante a gravidez, tentando adequar os seus comportamentos a esta situação. Para a autora, os pais mais conectados emocionalmente à gestação estariam mais predispostos a reagir adequadamente às necessidades de apoio e compreensão de suas esposas.

A grande incidência de envolvimento emocional relatada pelos pais do presente estudo pode estar relacionada ao período gestacional em que foram realizadas as entrevistas, $\mathrm{o} 3^{\circ}$ trimestre da gestação, período marcado pela proximidade do nascimento do bebê. A terceira fase do envolvimento paterno na gestação, proposta por May (1982), sugere que este é o período em que os pais estão mais conectados emocionalmente com a gestante, a fim de sentirem a gestação como algo presente em suas vidas e, desta maneira, prepararem-se para a paternidade. Soma-se a isto o apoio material relatado pelos pais, o qual também se apresenta como uma forma de envolvimento importante, pois, para alguns pais, ajudar fisicamente sua companheira constitui-se em uma forma de expressar seu interesse pelo bebê e agradá-la (Krob, 1999). Quanto a menor ocorrência de apoio material, em relação ao emocional - encontrada no presente estudo - podese pensar que a mudança no papel do pai, a qual se define por um maior envolvimento com a paternidade desde a gestação, pode não ter se traduzido em uma mudança efetiva em termos dos comportamentos destes pais. Neste sentido, Trindade, Andrade eSouza (1997) enfatizaram que, apesar de recentemente se poder verificar grandes transformações nas representações sociais dos papéis parentais, mudanças efetivas na divisão dos papéis no cotidiano ainda são incipientes.

O acompanhamento às consultas e exames pré-natais foi bastante relatado pelos pais como uma forma de participação na gravidez, sendo que quase todos acompanharam as ecografias realizadas por suas companheiras. O contato visual com o bebê, através da ecografia, desencadeou, em muitos pais, reações bastante positivas, proporcionando uma sensação de presença concreta do bebê. Parke (1996) enfatizou que a ecografia pode encorajar um maior interesse e envolvimento dos pais com o filho, uma vez que a observação do bebê em desenvolvimento costuma facilitar o apego paterno. Porém, alguns pais manifestaram uma certa incompreensão das imagens, o que, em certos casos, thes deu origem a uma vivência menos positiva ou até mesmo indiferente - da ecografia. Afora as eventuais dificuldades de um leigo para compreender as imagens deste exame, este tipo de reação pode estar associado a uma certa distância emocional dos pais em relação à gravidez. Assim, as dificuldades destes pais em sentir a gestação da companheira como real podem ser um indício de sentimentos ambivalentes quanto à paternidade (May, 1982).

O envolvimento nos preparativos para a chegada do bebê mostrou-se também bastante presente nos relatos dos pais. De acordo com Szejer e Stewart (1997), este tipo de participação mais ativa do pai representa uma grande ajuda para a companheira, além de ser uma forma de envolvimento que pode interessar sobremaneira os pais, pois faz com que eles se sintam realmente ocupados com a vinda de seu filho. De Martini (1999) afirmou que a participação do pai nos preparativos para a chegada do bebê tende a ser mais comum no $2^{\circ}$ trimestre, pois no primeiro a gestação ainda não é vista como algo concreto e visível, havendo ainda um grande risco de aborto. Além disso, neste momento o sexo do bebê ainda não é conhecido. Já no $3^{\circ}$ trimestre, a energia dos pais estaria bastante concentrada na sua preparação para a paternidade, em função da iminência do nascimento.

Mais de um terço dos pais referiu possuir conhecimentos sobre o desenvolvimento do seu bebê, obtidos no acompanhamento às ecografias, através das informações dadas pelo médico e pelas suas próprias observações e impressões. Isto indica o interesse destes pais pelo desenvolvimento de seus filhos, refletindo também suas preocupações a respeito da saúde do bebê, as quais mostraram-se marcantes nos dados do presente estudo, como será destacado abaixo. Contudo, merece atenção o fato de que apenas 4 participantes verbalizaram interesse na busca de informações sobre bebês e gravidez em revistas, jornais, programas de TV e em pessoas mais experientes. Somase a isto o fato de apenas 2 pais terem realizado o curso de gestante, o que também poderia lhes trazer importantes informações sobre o bebê, gestação e parto. Isto contraria os achados de Parke (1996) e Krob (1999), os quais verificaram que, durante a gestação, os pais procuram aprender sobre crianças e sobre a parentalidade através de leituras, bem como buscando troca de experiências com outros pais. Isto pode ser um indício de que, embora os pais estejam bastante envolvidos em alguns aspectos da gestação, esta permanece sendo um campo de interesse prioritariamente das mulheres. Desta forma, a busca de informações sobre o bebê seria um papel mais da mãe do que do pai, embora ambos, no presente estudo, estivessem sendo genitores pela primeira vez. Estes resultados parecem apoiar as idéias de Trindade (1993), pois, apesar da rejeição do modelo tradicional de paternidade - o qual permitia ao pai manter um distanciamento afetivo da familia - alguns aspectos deste modelo ainda mostram-se fortemente estabelecidos entre alguns casais. 
Os resultados revelaram, ainda, que pouquíssimos pais manifestaram desejo de assistir ao parto. Este dado parece indicar que o parto ainda é visto como algo essencialmente feminino, onde a participação do pai não encontra lugar. Esta idéia é, muitas vezes, reforçada pela equipe médica e pela organização hospitalar, visto que a participação do pai no trabalho de parto não é permitida em grande parte dos hospitais da rede pública de Porto Alegre. Além disto, o próprio pai pode sentirse despreparado para acompanhar a experiência do parto. Parke (1996) e Szejer e Stewart (1997) alertaram que, caso eles sejam pressionados a participar, poderão tornar o trabalho de parto mais complicado para todos os envolvidos. Klaus (1993) afirmou que a intensa ansiedade vivenciada por alguns pais frente à dor sofrida por sua parceira pode, muitas vezes, resultar em intervenções médicas desnecessárias. A autora colocou, ainda, que a experiência do parto pode causar extremo desgaste emocional para o pai. Este desgaste seria fruto da percepção da dor e do medo vivido pela parturiente, das preocupações vividas pelo próprio pai, em relação à saúde do bebê e da mãe, e da extrema exposição da intimidade de sua companheira, o que, em algumas culturas, é motivo de vergonha para o homem. Contudo, a equipe médica freqüentemente desconsidera toda esta carga emocional, exigindo do pai que acompanha o parto um papel que ele não têm condições de assumir, de extrema tranqüilidade e contenção das ansiedades da parturiente (Klaus, 1993).

Para que a presença do pai durante o parto seja positiva, ele necessita de treinamento e apoio (Szejer\& Stewart, 1997). Todavia, estes autores colocaram que os homens costumam ficar muito pouco à vontade nas sessões de preparação para o parto, sentindo-se deslocados. Por outro lado, os cursos de gestante, oferecidos em muitos hospitais de Porto Alegre, mostram em sua própria denominação um convite à mãe e uma exclusão ao pai, o que também é evidente em seu funcionamento, que muitas vezes não permite a participação dos pais. Acreditamos que esta inadequação dos cursos de preparação para o parto às necessidades dos pais pode ser uma das explicações para a pequena menção a estes cursos pelos participantes deste estudo. A exclusão do pai em alguns hospitais, tanto do exame ecográfico, como do curso de gestantes e do próprio parto, só tende a contribuir para que se exacerbem as dificuldades pessoais de vários pais com a gestação do seu filho e com a transição para a parentalidade.

Quanto à interação com o bebê, os resultados do presente estudo mostraram que a maioria dos pais interagia, de alguma forma, com seus filhos ainda durante a gestação. A percepção das manifestações do bebê gerava nestes pais grande emoção e alegria, além de permitir que estes atribuíssem características de personalidade ao filho, pois isto os certificava de que a criança já estava presente, fazendo parte de suas vidas. Os pais manifestaram, ainda, ter a impressão de que seu filho os reconhecia e respondia aos seus estímulos. Eles também declararam buscar ativamente a interação com o bebê, desejando um contato mais próximo com ele, através de conversas, da leitura de histórias, de carícias e beijos na barriga da gestante. Esta disponibilidade para a interação com o bebê reflete uma vivência já bastante real da paternidade, além de um grande envolvimento emocional com o bebê. Isto pode ser relacionado à última fase de envolvimento paterno proposta por May (1982), geralmente observada no $3^{\circ}$ trimestre de gestação, período em que se encontrava a amostra do presente estudo.

No entanto, alguns pais reclamaram da dificuldade de sentir os movimentos e reações do filho. Apareceram também alguns relatos de pouca interação com o bebê, o que pode decorrer destas dificuldades e/ou de sentimentos de inadequação. Talvez estes pais ainda não sentissem o bebê como real e presente em suas vidas, não conseguindo, por isso, comunicar-se com ele. Porém, todos os pais que revelaram ter pouca interação com seu filho, ainda assim, relataram alguma forma de interação ou reação frente às manifestações do bebê, mesmo que isto não acontecesse com freqüência. Isso nos leva a pensar que estes pais estavam, de alguma forma, envolvidos com seus filhos, apesar de suas dificuldades. Ainda a respeito da interação do pai com o bebê no período gestacional, não foram encontradas referências na literatura que enfoquem este aspecto do envolvimento paterno. Todavia, consideramos que este tipo de contato entre os pais e seus filhos não pode ser esquecido quando se pretende compreender o envolvimento do pai na gestação, bem como após o nascimento do bebê.

Os resultados do presente estudo revelaram ainda que os pais manifestaram diversas preocupações durante a gravidez de suas companheiras. Este achado corrobora o estudo realizado por Krob (1999), segundo o qual a gestação seria um período marcado por sentimentos ambivalentes de alegria e ansiedade, e também de alguns conflitos. Os dados mostraram que a maior parte das preocupações referidas pelos pais relacionou-se com a saúde e bem-estar do bebê e da gestante, o que indica a existência de um envolvimento emocional com ambos. Alguns pais, embora em menor freqüência, também relataram preocupações em relação ao trabalho de parto e/ou tipo de parto. A este respeito, Parke (1996) afirmou existirem homens que se preocupam mais que suas esposas com o sofrimento e dores do parto. Do mesmo modo, os pais entrevistados por Krob mostraram-se bastante preocupados com este evento, com dúvidas a respeito de como ele se daria, se tudo correria bem para a mãe e o bebê, e se seria um momento tranqüilo e sem complicações.

Contudo, chama atenção que a grande maioria dos entrevistados do presente estudo não relatou preocupação com o parto, o que contrasta com a complexidade deste momento e com as ansiedades que sua vivência desperta para todos os envolvidos, conforme discutido anteriormente. Talvez a institucionalização do parto, bem como o papel secundário 
delegado ao pai neste evento, sejam alguns dos fatores que expliquem esta aparente despreocupação. Mesmo assim, conforme Espírito Santo e Bonilha (2000), é preciso compreender que a medicalização do parto não atinge somente os pais, mas também as mães, pois a equipe médica se "apropria" deste momento tirando da mãe a confiança na sua capacidade de dar à luz e do homem o direito de participar do nascimento de seu filho. Em um estudo realizado em um grande hospital universitário de Porto Alegre, estas autoras constataram que as equipes obstétricas têm restringido sistematicamente a participação dos pais no parto e nascimento do filho, mesmo em situações que apresentam poucos riscos. Segundo as autoras, a autorização para que o pai possa assistir ao parto é dada somente no último momento, sendo que quando acontece a negativa, esta geralmente não é justificada pelos profissionais. No estudo de Espírito Santo e Bonilha a grande maioria dos pais entrevistados assinalaram o desejo de assistir ao parto sendo que aqueles que não puderam participar expressaram frustração e forte ansiedade. Estes achados contrariam, deste modo, os dados do presente estudo. Apesar de muitos profissionais e futuros pais acreditarem na importância da participação do pai no parto, deve-se relembrar que, para alguns pais, a vivência deste importante momento pode ser traumática ou mesmo insuportável. Portanto, a participação do pai não deveria ser uma prescrição, mas uma possibilidade, um convite, cuja decisão deveria ser respeitada e apoiada pelos técnicos e familiares.

Em relação às preocupações financeiras, embora estivessem presentes na fala de vários pais, elas também não foram as preocupações predominantes para os entrevistados do presente estudo. Este achado não corrobora a afirmação de Parke (1996) de que o dinheiro seria a principal preocupação dos pais durante a gestação, contestando a visão tradicional do papel do pai como restrito à provisão das necessidades materiais do bebê (Brazelton, 1988). A partir disto, podemos constatar que os relatos dos pais entrevistados parecem refletir uma mudança no papel paterno, a qual diz respeito à maior participação do pai nos cuidados com o bebê. Esta mudança já foi apontada por diversos autores (Fein, 1978; Muzio, 1998; Rezende \& Alonso, 1995), e, segundo Burdon (1998), estaria associada, às novas configurações sociais e econômicas que permitiram a entrada em massa das mulheres no mercado de trabalho e, conseqüentemente, a maior participação dos homens nas tarefas domésticas e na criação de crianças.

Ainda assim, a afirmação de Parke (1996) de que a ansiedade quanto aos gastos com o bebê faria com que os pais aumentassem sua carga horária de trabalho, ou assumissem um segundo emprego, encontrou respaldo nas verbalizações de alguns participantes deste estudo. Houve pais que buscaram um novo emprego depois da notícia da gestação, a fim de aumentar a renda familiar, enquanto outros referiram temer pela instabilidade de seu emprego. As preocupações com o aumento das responsabilidades também se fizeram presentes nos relatos dos pais. Do mesmo modo, Krob (1999) verificou que alguns dos pais por ela entrevistados acreditavam que o nascimento do bebê traria mais responsabilidades, e envolveriam tanto suporte material como emocional, que estes pais deveriam dispor para oferecerem aos seus filhos.

É importante assinalar que quase um terço dos pais do presente estudo relataram literalmente não ter preocupações com a gestação, embora alguns destes tenham referido preocupações em outros momentos da entrevista. Pode-se pensar que estes pais estivessem negando estas preocupações, por ser demasiadamente penoso para eles darem-se conta de seus medos e angústias referentes à mãe e ao bebê. Isto pode estar também relacionado ao estereótipo masculino, que exige do homem um maior controle de suas emoções. Ao mesmo tempo, esta aparente tranqüilidade pode estar associada à necessidade dos pais de oferecerem-se como uma figura de apoio à gestante, contendo as ansiedades próprias deste período.

\section{Considerações Finais}

A partir do presente estudo, verificou-se a presença de um expressivo envolvimento dos pais na gestação, tanto em termos emocionais como comportamentais. Este envolvimento foi manifestado através dos relatos de preocupações e ansiedades dos pais, de apoio material e emocional prestado à gestante, da sua participação em diversas atividades relativas à gestação e da sua interação com o bebê. Juntos, estes dados revelam indícios de uma profunda modificação quanto à paternidade no período da gestação, a qual parece não se encontrar mais restrita ao universo feminino, pelo menos na vida de muitos dos casais investigados. No entanto, alguns pais demonstraram dificuldade em atender integralmente a este novo papel paterno, de maior participação e envolvimento. Estes pais, embora em menor número, merecem referência particular por apresentarem dificuldades de se aproximarem emocionalmente da gestante e do bebê, não conseguindo perceber, por vezes, o seu filho como vivo e real. Na verdade, mesmo os pais mais envolvidos durante a gestação, também evidenciaram algumas restrições quanto a sua participação. Isto apareceu, por exemplo, no fato de que a grande maioria dos pais não manifestou o desejo de assistir ao parto, nem tampouco relatou interesse em participar de cursos de gestantes ou de buscar conhecimentos sobre o desenvolvimento do bebê em livros, revistas ou recursos da mídia em geral. 
Deste modo, os pais demonstraram que o envolvimento paterno durante a gestação ainda encontra algumas barreiras, sejam estas subjetivas ou externas. Isso traz implicações para o envolvimento ativo dos pais não só neste período investigado da gestação, mas, provavelmente, também após o nascimento do bebê, quando a estas dificuldades paternas soma-se, por vezes, a resistência de algumas mulheres à participação dos companheiros nos cuidados do bebê (Burdon, 1998). Contudo, resta refletir se os estudiosos e a sociedade de modo geral, não estão exigindo do pai um envolvimento que está além de suas possibilidades, desconsiderando eventuais diferenças sexuais ou particularidades da maternidade e paternidade. Em realidade, a experiência física e emocional da gestação é bastante distinta para homens e mulheres e isto, provavelmente, tem conseqüências particulares para cada um deles, mas também enriquece a relação triádica mãe-pai-bebê. Neste sentido, Szejer e Stewart (1997) afirmaram que homens e mulheres apresentam recursos e reações muito diferentes e, portanto, seria mais útil a busca por ações complementares, ao invés de paralelas. O envolvimento paterno durante a gestação é um tema ainda pouco abordado em pesquisas psicológicas. No entanto, a investigação desta temática é de extrema importância, pois vários autores atestam o papel do pai já na gestação tanto no estabelecimento do apego pai-bebê como para o desenvolvimento na criança, de um senso de confiança e segurança (Costa \& Katz, 1992; Parke, 1996; Silveira, 1998). Tomando os achados do presente estudo, recomenda-se que futuras pesquisas focalizem os diferentes estilos de envolvimento paterno (Parke, 1996), os aspectos transgeracionais relacionados ao envolvimento emocional do pai (Bowlby, 1989; Lamb, 1997) e os fatores culturais e sociais que podem estar determinando a quantidade e a forma de envolvimento desses pais na gestação (Burdon, 1998; Lewis \& Dessen, 1999). O conhecimento daí advindo permitiria que fossem planejadas estratégias de prevenção e de intervenção, focalizando, principalmente, aqueles pais que manifestassem mais dificuldades em relação ao envolvimento com seus filhos.

\section{Referências}

Bardin, L. (1977). Análise de conteúdo. São Paulo: Edições 70.

Bowlby, J. (1989). Uma base segura: Aplicacões clínicas da teoria do apego. Porto Alegre: Artes Médicas.

Brazelton, T. B. (1988). O desenvolvimento do apego: Uma família em formação. Porto Alegre: Artes Médicas.

Brazelton, T. B. \& Cramer, B. G. (1992). As primeiras relações. São Paulo: Martins Fontes.

Burdon, B. (1998). Envolvendo os homens na vida familiar: Se eles podem fazê-lo, porque não o fazem. Em P. Silveira (Org.), Exerćcicio da paternidade (pp 81 - 90). Porto Alegre: Artes Médicas.
Costa, G. P. \& Katz, G. (1992). Dinâmica das relações conjugaiis. Porto Alegre: Artes Médicas.

De Martini, T. A. D. (1999). A transição para a parentalidade: Expectativas, sentimentos e sindrome de couvade dos futuros pais ao longo da gestação. Dissertação de Mestrado não-publicada, Programa de Pós-graduação em Psicologia do Desenvolvimento, Universidade Federal do Rio Grande do Sul. Porto Alegre, RS.

Delmore-Ko, P., Pancer, S. M., Hunsberger, B. \& Pratt, M. (2000). Becoming a parent: The relation between prenatal expectations and postnatal experience. Journal of Family Psychology, 14, 625-640.

Espírito Santo, L. C. \& Bonilha, A. L. (2000). Expectativas, sentimentos e vivências do pai durante o parto e nascimento de seu filho. Revista Gaúcha de Enfermagem, 21(2), 87-109.

Fein, R. A. (1978). Research on fathering: Social policy and an emergent perspective. Journal of Social Issues, 34(1), 122-135.

Grupo de Interação Social, Desenvolvimento e Psicopatologia (1998a). Ficha de contato Inicial. Porto Alegre: Instituto de Psicologia, UFRGS. (Instrumento não-publicado)

Grupo de Interação Social, Desenvolvimento e Psicopatologia (1998b). Entrevista de dados demográficos do casal. Porto Alegre: Instituto de Psicologia, UFRGS. (Instrumento não-publicado)

Grupo de Interação Social, Desenvolvimento e Psicopatologia (1998c). Entrevista sobre a gestacão e as expectativas do futuro pai. Porto Alegre: Instituto de Psicologia, UFRGS. (Instrumento não publicado)

Hollingshead, A. (1975). The four-factor index of social status. Yale University. (Manuscrito não-publicado)

Klaus, P. (1993), O novo pai. Em Associação Brasileira para o Estudo do Psiquismo Pré e Perinatal (Org.), Anais, $1^{\circ}$ Encontro Brasileiro para o Estudo do Psiquismo Pré $e$ Perinatal (pp. 62-76). São Paulo, SP: ABEPPP.

Klaus, M. H. \& Kennell, J. H. (1992). Pais/ bebê: A formação do apego. Porto Alegre: Artes Médicas.

Krob, A. D. (1999). A transição para a paternidade e a interação pai-bebê. Dissertação de Mestrado não-publicada, Programa de Pós-graduação em Psicologia do Desenvolvimento, Universidade Federal do Rio Grande do Sul. Porto Alegre, RS.

Lamb, M. E. (Ed.) (1997). The role of the father in cbild development. New York: John Wiley.

Lamb, M. E., Pleck, J. H., Charnov, E. L. \& Levine, J. A. (1985). Paternal behavior in humans. American Zoologist, 25, 883-894.

Lewis, C. \& Dessen, M. A. (1999). O pai no contexto familiar. Psicologia: Teoria e Pesquisa, 15, 09-16.

Levy-Shiff, R. \& Israelashvili, R. (1988). Antecedents of fathering: Some further exploration. Developmental Psychology, 24, 434-440.

Maldonado, M. T., Dickstein, J. \& Nahoum, J. C. (1997). Nós estamos grávidos $\left(10^{2}\right.$ ed.). São Paulo: Saraiva.

May, K. A. (1982). Three phases of father involvement in pregnancy. Nursing Research, 31, 337-342.

Muzio, P. A. (1998). Paternidade (ser pai)... Para que serve? Em P. Silveira (Org.), O exercício dapaternidade (pp. 165-174). Porto Alegre: Artes Médicas.

Pascual, L., Galperin, C. Z. \& Bornstein, M. H. (1995). La medición del nivel socioeconómico y la psicolgia evolutiva (Measurement of socioeconomic status and developmental psychology). Revista Interamericana de Psicologia, 27, 59-74.

Parke, R. D. (1996). Fatherhood. Cambridge, Massachusetts: Harvard University Press.

Piccinini, C. A., Tudge, J., Lopes, R. S. \& Sperb, T. M. (1998). Estudo longitudinal de Porto Alegre: Da gestação à escola. Porto Alegre: Instituto de Psicologia, UFRGS. (Projeto de pesquisa)

Pleck, J. H. (1997). Paternal involvement: Levels, sources, and consequences. Em M. Lamb (Org.), The role of the father in child development (pp. 66-103 ). New York: John Wiley \& Sons. 
Rezende, A. L. \& Alonso, I. L. (1995). O perfil do pai cuidador. Revista Brasileira de Crescimento e Desenvolvimento Humano, 5, 66-81.

Ribas, R. de C., Jr., Seidl de Moura, M. L. \& Bornstein, M. H. (no prelo). Socioeconomic status in Brazilian psychological research: II SES and parenting knowledge. Estudos de Psicologia.

Salmela-Aro, K., Nurmi, J., Saisto, T. \& Halmesmãki, E. (2000). Women’s and men's personal goals during the transition to parenthood. Journal of Family Psychology, 14, 171-186.

Silveira, P. (1998). Exercício da paternidade. Porto Alegre: Artes Médicas.

Souza, S. L. (1997). O papel do pai. Em M.Zugaib, I. Tedesco \& I. Awayle (Orgs.), Obstetrícia psicossomática (pp 62-70). São Paulo: Atheneu.
Szejer, M. \& Stewart, R. (1997). Nove meses na vida da mulher. São Paulo: Casa do Psicólogo.

Trindade, Z. A. (1993). As representações sociais e o cotidiano: A questão da maternidade e da paternidade. Psicologia: Teoria e Pesquisa, 9, 535-546.

Trindade, Z. A., Andrade, C. A. \& Souza, J. Q. (1993). Papéis parentais e representações da paternidade: A perspectiva do pai. Psico, 28, 207-222.

Winnicott, D. W. (1966). A criança e o seu mundo. Rio de Janeiro: Zahar.

Recebido:07/08/2003

$1^{a}$ Revisão: $15 / 10 / 2003$

Aceite Final: 31/10/2003

Sobre os autores

César Augusto Piccinini é Professor do Programa de Pós-graduação em Psicologia do Desenvolvimento da Universidade Federal do Rio Grande do Sul.

Milena da Rosa Silva é Mestre e Doutoranda pelo Programa de Pós-graduação em Psicologia do Desenvolvimento da Universidade Federal do Rio Grande do Sul.

Tonantzin Ribeiro Gonçalves é aluna do Instituto de Psicologia da Universidade Federal do Rio Grande do Sul. É bolsista CNPq.

Rita Sobreira Lopes é Professora no Programa de Pós-graduação em Psicologia do Desenvolvimento da Universidade Federal do Rio Grande do Sul.

Jonathan Tudge é Professor na University of North Carolina at Greensboro, EUA. É pesquisador associado ao Programa de Pós-graduação em Psicologia do Desenvolvimento da Universidade Federal do Rio Grande do Sul. 